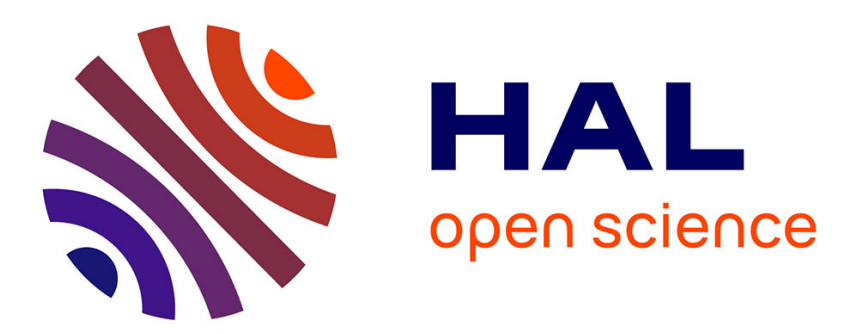

\title{
Adsorption characterization of various modified $\beta$-cyclodextrins onto TEMPO-oxidized cellulose nanofibril membranes and cryogels
}

Bastien Michel, Anne Imberty, Ellinor Heggset, Kristin Syverud, Julien Bras, Alain Dufresne

\section{To cite this version:}

Bastien Michel, Anne Imberty, Ellinor Heggset, Kristin Syverud, Julien Bras, et al.. Adsorption characterization of various modified $\beta$-cyclodextrins onto TEMPO-oxidized cellulose nanofibril membranes and cryogels. Sustainable Chemistry and Pharmacy, 2021, 24, pp.100523. 10.1016/j.scp.2021.100523 . hal-03361958

\section{HAL Id: hal-03361958 \\ https://hal.science/hal-03361958}

Submitted on 5 Oct 2021

HAL is a multi-disciplinary open access archive for the deposit and dissemination of scientific research documents, whether they are published or not. The documents may come from teaching and research institutions in France or abroad, or from public or private research centers.
L'archive ouverte pluridisciplinaire HAL, est destinée au dépôt et à la diffusion de documents scientifiques de niveau recherche, publiés ou non, émanant des établissements d'enseignement et de recherche français ou étrangers, des laboratoires publics ou privés. 


\title{
Adsorption characterization of various $\beta$-cyclodextrins onto TEMPO- oxidized cellulose nanofibrils nanofibril membranes and cryogels
}

\author{
Bastien Michel ${ }^{1}$, Anne Imberty ${ }^{2}$, Ellinor B. Heggset ${ }^{3}$, Kristin Syverud ${ }^{3,4}$, Julien Bras ${ }^{1}$, Alain \\ Dufresne $^{1}$
}

\footnotetext{
1 Univ. Grenoble Alpes, CNRS, Grenoble INP, LGP2, 38000 Grenoble, France, bastien.michel@lgp2.grenoble-inp.fr (B.M.), julien.bras@grenoble-inp.fr (J.B.), alain.dufresne@grenoble-inp.fr (A.D.)

2 Univ. Grenoble Alpes, CNRS, CERMAV, 38000 Grenoble, France.

3 RISE PFI, NO-7491 Trondheim, Norway, ellinor.heggset@rise-pfi.no (E.B.H.), kristin.syverud@rise-pfi.no (K.S.)

4 Departments of Chemical Engineering, NTNU, 7491 Trondheim, Norway, kristin.syverud@rise-pfi.no
}

\begin{abstract}
TEMPO-Oxidized cellulose nanofibrils (toCNF), in the form of highly entangled network, such as in membrane or cryogels, have proven to be interesting for various applications, including drug release or purification. $\beta$-Cyclodextrins ( $\beta$-CDs) have the ability to form inclusion complexes with hydrophobic molecules, and are considered as a promising way to bring new functionalities to these materials, by reducing burst release effect or improving the purification properties. The study of the adsorption between toCNF and $\beta$-CDs is then crucial to design toCNF/ $\beta-C D s$ materials, but is very complex due to the chemical proximity between these compounds. In this study, we develop toCNF cryogels containing various types of $\beta$-CDs by physical mixing as well as different protocols for analysis of the interactions between these compounds, such as Isothermal Titration Calorimetry (ITC), Quartz-Crystal Microbalance with dissipation monitoring (QCM-d) and a Phenolphtalein-based protocol (PhP protocol). Adsorption between $\beta-C D$ and toCNF was proven at two different temperatures with ITC. QCM-d measurements allowed to measure adsorption of different $\beta$-CDs onto toCNF, with higher adsorption measured for the modified $\beta$-CDs, and with estimated binding capacity ranging from 13.4 to $47.6 \mu \mathrm{mol} / \mathrm{gtoCNF}$. $\mathrm{PhP}$ protocol allowed us to monitor the amount of $\beta$-CDs released in aqueous environment, highlighting a lower release for modified $\beta$-CDs onto toCNF, and the results were consistent with the estimated binding capacity. This quantification of the binding capacity of various $\beta$-CDs allows for an optimization of the design of toCNF/ $\beta-C D$ s materials.
\end{abstract}

Keywords: nanocellulose, $\beta$-cyclodextrin, cryogels, adsorption, ITC, QCM-d 


\section{INTRODUCTION}

Through the combination of various chemical and/or enzymatic pretreatments and mechanical treatments, cellulose nanofibrils (CNFs) can be isolated from cellulose fibers [1]. CNFs are high aspect ratio nanoparticles, formed by bundles of cellulose chains, which consist of repeating anhydroglucose units (AGU) linked by $\beta-1-4$ glycosidic bonds. Amongst the various pre-treatments used, is the so-called TEMPO-oxidation, proposed by Saito et al. in 2006 [2]. TEMPO-oxidation consists of regioselective oxidation of C6 primary hydroxyls of cellulose to C6 carboxylate groups in the presence of (2,2,6,6-tetramethyl-piperidin-1-yl)oxyl, also known as TEMPO. TEMPO-oxidised cellulose nanofibrils (toCNFs) exhibit high carboxylic groups contents and reduced size, making them interesting for specific applications. More generally, the excellent properties of CNFs have made them a material of choice for a wide variety of applications, as shown by recent reviews [3]-[5]. The ability of CNFs and toCNFs to form entangled networks, their chemical surface tunability, their sorption properties and biocompatibility have made them particularly suited for drug release [6] or filtration applications, such as water purification [7]. Even if these materials have been proven to be promising for such applications, there is still huge room for improvements, more specifically reducing the burst release effect for drug release applications or improving the entrapment properties for filtration. Among the various strategies of improvement envisaged, the use of cyclodextrins (CDs) seems to be one of the most promising.

CDs are macromolecules enzymatically derived from starch, composed of AGU linked by $\alpha-1-4$ glycosidic bonds. The 3 CDs most frequently encountered are the $\alpha-C D, \beta-C D$ and $\gamma-C D$, composed of 6, 7 and 8 AGU, respectively. These cyclic oligosaccharides exhibit cage-like properties linked to their specific conformation. Indeed, with their hydrophilic outer surface and hydrophobic central core, CDs have the properties to form inclusion complexes with lipophilic compounds. Due to this feature, CDs have been widely used for numerous applications [8], such as drug excipient [9] or selective extraction of pollutants [10]. Because to its specific cavity size, $\beta$ $\mathrm{CD}$ can form inclusion complexes with aromatic compounds, making it suitable for a high number of molecules of interest. Despite its low solubility in water (around 18g/L), $\beta-C D$ is the most produced $C D$ [11]. $\beta-C D$ solubility can be improved via chemical modification. Indeed, substitution of any of the hydrogen bond-forming hydroxyl groups results in improved aqueous solubility [12]. Additionally, the chemical modification of CDs, made possible through the presence of hydroxyl groups in the C2, C3 (secondary hydroxyls) and C6 (primary hydroxyls) positions available on each glucose unit, can also bring new functionalities to the produced CDs. Of these derivatives, the most common is 2 -Hydroxypropyl $\beta$-Cyclodextrin (HP- $\beta-C D)$. HP- $\beta-C D$ is usually produced by the reaction of $\beta-\mathrm{CD}$ with propylene oxide in alkaline medium [13]. This derivative is highly soluble and has been proven to be non-toxic [14], making HP- $\beta-C D$ one of the most produced $\beta-C D$ derivatives. Another interesting derivative is Carboxymethyl- $\beta$ Cyclodextrin (CM- $\beta-C D)$. This derivative is usually synthetized by reacting $\beta-C D$ with chloroacetic acid under alkaline condition [15], [16]. The carboxylic groups introduced to the CD offer new possibilities for grafting or adsorption of these derivatives onto substrates in order to bring the inclusion capabilities of $\beta-C D$ into different application areas. These derivatives were first used for chiral analysis techniques [17], but studies on the use of these derivatives for biomedical applications are also being conducted, showing promising results [18]. There have been attempts also to cross-link cyclodextrins, to obtain a polymer of $\beta$-CDs. Different protocols 
exist, using various cross-linkers, such as epichlohydrin, resulting in insoluble polymers [19], or poly-carboxylic acids, resulting in water-soluble polymers [20]. Thus, the functionalization of materials with native or modified cyclodextrins can be considered in order to combine the original properties of the materials with the complexing properties of cyclodextrins.

The combination of $\beta$-CDs with nanocellulose is reported in several studies [21]-[32]. One possible strategy is the use of a cross-linker between nanocellulose and cyclodextrins .RuizPalomero et al. [23] reported the functionalization of toCNF with CM- $\beta-C D$, via $N$-ethyl- $N^{\prime}-(3-$ (dimethylamino)propyl)carbodiimide/ $N$-hydroxysuccinimide (EDC/NHS) activation and used a diamine as cross-linker, for the adsorption of danofloxacin, an antibiotic contained in milk. Yuan et al. [22] used citric acid as a cross linker to graft $\beta C D$ and $\gamma$-CD on regenerated cellulose fibers for adsorption of toluene. Castro et al. [27] used different carboxylic acids as cross-linker between toCNF and $\beta-\mathrm{CD}$ and reported better encapsulation of carvacrol for modified materials. Benefits of this strategy are the potential detection of the cross-linking agent, allowing an estimation of the yield of grafting. However, the potential trace of cross-linking agent can be an obstacle for biomedical applications. Another strategy would be the grafting via thermal treatment. In 2016, Saini et al. [21] grafted $\beta$-CD on the carboxyls groups of toCNF via esterification by thermal treatment under vacuum, and reported a reduction in burst effect for the release of carvacrol and an improvement in antimicrobial activity. The benefits of this strategy are the potential proof of esterification available with spectroscopic measurements. Additionally, the absence of crosslinking agent could be beneficial for medical applications. Finally, a last strategy is the adsorption of cyclodextrins on nanocellulose with no further chemical reactions. Lavoine et al. [25] reported the design of a controlled release system of chlorhexidine gluconate by coating onto a paper substrate a mixture of $\beta-C D$ and micro-fibrillated cellulose. However, they pointed out the difficulty of assessing the adsorption and its characterization.

The main difficulty with the combination of $\beta$-CDs and nanocelluloses is the chemical similarity of these two components. Both cellulose and cyclodextrins have the same repeating units, linked by $\beta-1,4$ glycosidic bonds in the case of cellulose and $\alpha-1,4$ glycosidic bonds in the case of $\beta-C D$. Different experimental methods can be considered to study the adsorption between cyclodextrins and nanocelluloses. Quartz Cristal Microbalance with dissipation monitoring (QCM-d) has been used to assess the functionalization of cellulose nanofibrils with $\beta-C D$ and poly $\beta-C D$ by GomezMaldonado et al. [31], but they highlighted the challenges of assessing the amount of cyclodextrins attached to CNF. A protocol to quantify the amount of cyclodextrins grafted onto toCNFs has been proposed by de Castro et al. [29], based on the use of phenolphthalein. A recent work studied the thermodynamics of absorption of molecules on nanocelluloses by Isothermal Titration Calorimetry (ITC) [33]-[35], which make it conceivable to measure the absorption of cyclodextrins by this method.

The aim of this study is to characterize the adsorption between toCNF and cyclodextrins by using different protocols. The implementation of three different protocols, namely ITC, QCM-d and $\mathrm{PhP}$, will allow the characterization of the possible adsorption phenomena in a complete way and to obtain a quantification of the adsorbed CDs. The use of different cyclodextrins $(\beta-C D, H P-\beta-$ $\mathrm{CD}, \mathrm{CM}-\beta-\mathrm{CD}$ and poly $\beta-\mathrm{CD}$ ) will allow us to verify whether the chemical makeup of the modified cyclodextrins has an impact on the quantity of adsorbed cyclodextrins. Finally, the 
combination of the three protocols for the different cyclodextrins will help us to identify the best way to design materials for controlled release applications.

\section{MATERIALS AND MEthODS}

\subsection{MATERIALS}

A $1 \mathrm{wt} \%$ toCNF suspension was purchased from the University of Maine. $\beta$-Cyclodextrin $(\beta-C D$, $\mathrm{M}=1134.98 \mathrm{~g} / \mathrm{mol}), 2-H y d r o x y p r o p y l-\beta-C y c l o d e x t r i n(H P-\beta-C D, D S=3, M=1380 \mathrm{~g} / \mathrm{mol}$ ) and the polymer of $\beta-C D(M \approx 1190 \mathrm{~g} / \mathrm{mol})$ were purchased from Sigma-Aldrich. Carboxymethyl- $\beta$ Cyclodextrin Sodium Salt (CM- $\beta-C D, D S=3.5, M=1415 \mathrm{~g} / \mathrm{mol}$ ) was purchased from CycloLab. Other chemicals were of laboratory grade and purchased from Sigma-Aldrich.

\subsection{Methods}

\subsubsection{CELLULOSE NANOFIBRILS CHARACTERIZATION}

\subsubsection{CONDUCTOMETRIC TITRATION}

Conductometric titration was carried out to measure the total amount of carboxyl groups in the neat toCNF suspension. $0.2 \mathrm{~g}$ of dry content of toCNF was dispersed in $200 \mathrm{~mL}$ of distilled water. The $\mathrm{pH}$ was then adjusted to approximately 2.5 by adding $0.1 \mathrm{M} \mathrm{HCl}$. Then, the suspension was titrated with $0.05 \mathrm{M} \mathrm{NaOH}$ by adding $0.1 \mathrm{~mL}$ every $30 \mathrm{~s}$ until the $\mathrm{pH}$ was up to 11 . The total carboxylate content was calculated on the basis of $\mathrm{NaOH}$ volume with equation 1 .

$$
\text { Charge rate }=\frac{C_{\mathrm{NaOH}} \times V_{e q}}{m}
$$

Where $\mathrm{C}_{\mathrm{NaOH}}$ is the concentration of the $\mathrm{NaOH}$ solution, $\mathrm{V}_{\text {eq }}$ the volume of $\mathrm{NaOH}$ corresponding to volume consumed in the second intersection point for weak acids, and $\mathrm{m}$ is the dry content of toCNF. This measurement was done in triplicate.

\subsubsection{ELECTRON MICROSCOPIES}

Scanning electron microscopy (SEM) images were performed with ESEM (Quanta 200, FEI, Japan). Cryogel cross-sections were cut with a razor blade. SEM observation was carried out on cross-sections after carbon sputter coating of $5 \mathrm{~nm}$, with a tension of $10 \mathrm{kV}$ and a spot size of 3.5 . The working distance was set between $9.5 \mathrm{~mm}$ and $11.5 \mathrm{~mm}$ depending on the sample.

Transmission electron microscopy (TEM) images were performed with a JEOL JEM 2100-Plus microscope operating at $200 \mathrm{kV}$. Samples were deposited on copper grids, and uranyl acetate was used as negative staining.

\subsubsection{CRYOGEL PROCESSING}

Material processing used in the study is similar to the one reported in a previous study [32]. Suspensions at $0.8 \% \mathrm{wt}$ toCNF were prepared at $50 \mathrm{~mL}$ volume in distilled water $(0.4 \mathrm{~g}$ of dry matter). The suspensions were dispersed for $2 \mathrm{~min}$ at $7000 \mathrm{rpm}$ with an UltraTurrax. Cyclodextrins $(0.04 \mathrm{~g})$ were added and the suspensions were magnetically stirred for 1 hour and placed in an ultra-sonic bath for 3 minutes. The suspensions were poured into a 24 -well plate ( $3 \mathrm{~mL}$ per well) and put in a freezer at $-20^{\circ} \mathrm{C}$ for $24 \mathrm{~h}$ before freeze drying for $48 \mathrm{~h}$ at $0.04 \mathrm{mbar}$ (ALPHA 2-4 LDplus, Christ $\left.{ }^{\circledR}\right)$. The resulting cryogels were stored in closed well-plates at room temperature.

\subsubsection{POROSITY AND ABSORBENCY CAPACITY}


Absorbency capacity test on cryogels were conducted gravimetrically. The cryogels were weighted and immersed in distilled water, and then removed at different times. Excess water was removed before weighting. Water sorption was calculated using equation 2 .

$$
\text { Absorbency capacity }[\mathrm{g} / \mathrm{g}]=\frac{m_{\text {swollen }}-m_{\text {dry }}}{m_{\text {dry }}}
$$

The volume of produced cryogels was measured from height and diameter measurements using a calliper. The relative density of cryogels was calculated from the ratio Q/ Qc, where Qc is the density of cellulose, $1.5 \mathrm{~g} / \mathrm{cm}^{3}$ [36]. The porosity was calculated from equation 3 .

$$
\text { Porosity }=\left(1-\frac{\rho}{\rho_{C}}\right) \quad \text { (Eq. 3) }
$$

\subsubsection{ISOTHERMAL TITRATION CALORIMETRY}

Isothermal Titration Calorimetry experiments were performed with a VP ITC (Microcal inc) e. ITC is a method developed to determine the thermodynamic parameters during the interaction between two molecules. This method is based on the measurement of the heat released during the interaction between the two molecules during a titration. First developed for molecules in solution, this method has recently been used to measure interactions between a molecule in solution and a molecule in suspension, in particular nanocellulose suspensions [33]. A sample cell with a volume of $1.8 \mathrm{~mL}$ was filled with aqueous toCNF suspensions ( $2 \mathrm{mg} / \mathrm{ml}$ in MilliQ water). ITC experiments were carried out at $25^{\circ} \mathrm{C}$ and $35^{\circ} \mathrm{C}$ by injecting $10 \mu \mathrm{L}$ of aqueous $\beta-\mathrm{CD}$ solution ( $1 \mathrm{mM}$ in MQ water) from a $280 \mu \mathrm{L}$ injection syringe into the sample cell, which was stirred at 307 rpm to ensure optimal mixing efficiency. To determine the heat of dilution of $\beta-C D$, blank titrations were made by injecting the $\beta-C D$ solution into the cell filled with MQ water. The enthalpy curve of heat of dilutions was then subtracted from the curves of interactions between toCNF and $\beta-C D$. Data were fitted with one site model of interaction with MicroCal PEAQ-ITC Analyzer Software, according to standard procedures. Fitted data yielded the stoichiometry (n), the association constant $(\mathrm{Ka})$, and the enthalpy of binding $(\Delta \mathrm{H})$. Two independent titrations were performed for each ligand tested.

\subsubsection{QUARTZ CRISTAL MICROBALANCE WITH DISSIPATION}

The principle of the QCM-d was first described by Rodahl et al. [37]. It is based on the changes in frequency of a piezoelectric sensor. The sensor has a base resonance of $5 \mathrm{MHz}$ and its respective overtones. These frequencies are monitored as the sensor is in contact with a flow of matter. When the mass of the sensor changes, i.e. molecules are adsorbed on its surface, the frequency changes and the shift in frequency is linked to the mass of material adsorbed. This mass can be calculated according to the Sauerbrey equation (eq. 4):

$$
\Delta m=-C \frac{\Delta f}{n}
$$

Where $C$ is a constant related to the density and thickness of the quartz crystals $\left(C=17.7 \mathrm{ng} / \mathrm{cm}^{2}\right)$, $\Delta \mathrm{f}$ is the shift in frequency and $\mathrm{n}$ is the overtone number. It is worth noting that this model is valid if the created films are rigid, uniform and if the mass is small compared to the mass of the crystal. Other models have been developed [38] but for our systems we will use Sauerbrey's.

In situ formation of toCNF surfaces on gold sensors and the adsorption of CDs were studied with a QSense Analyzer from Biolin Scientific. QCM-d sensors were cleaned by dipping them $30 \mathrm{~min}$ 
in a Piranha bath $\left(1: 3 \mathrm{H}_{2} \mathrm{O}_{2} / 2 / 3 \mathrm{H}_{2} \mathrm{SO}_{4}\right)$. After cleaning, the sensors were rinsed by successive immersions in distilled water and dried with nitrogen. Sensors were then spin-coated with PEI, the anchoring polymer. After spin coating, the sensors were placed in the QCM-d apparatus and stabilized under a $100 \mu \mathrm{L} / \mathrm{min}$ distilled water flow, for a minimum of 10 minutes of stabilization before the toCNF flow (adsorption step), followed by a rinsing step with distilled water. toCNFs and CDs solutions were prepared at $0.1 \mathrm{wt} \%$ in distilled water and flowed at a rate of $100 \mu \mathrm{L} / \mathrm{min}$. A minimum of 10 minutes of stabilization time was done after each step (rinsing step, adsorption step). Calculations were made using the third overtone.

\subsubsection{PHENOLPHTHALEIN PROTOCOL}

Phenolphthalein is a phenolate ion which is colored purple in alkaline solution but loses its color when forming an inclusion complex with $\beta$-CD [39]. The decrease in absorbance when increasing the $\beta$-CD content has been proved to follow an exponentially decreasing curve [40]. A calibration curve of the concentration of $\beta$-CDs according to the absorbance of a PhP solution can therefore be built by UV spectrophotometry by plotting the logarithmic concentration of $\beta-C D$ against the logarithmic absorbance value at $554 \mathrm{~nm}$.

\subsubsection{CALiBRATiOn CURVES}

A working solution of $375 \mu \mathrm{M} \mathrm{PhP}$ in $\mathrm{EtOH}, 28 \mathrm{mM} \mathrm{Na}_{2} \mathrm{CO}_{3}$ solution in distilled water, $15 \mathrm{mM}$ stock solution of CDs in distilled water and $\mathrm{pH} 12.5$ buffer were prepared. The calibration curves were built by preparing solutions composed of $1 \mathrm{~mL}$ PhP: $1 \mathrm{~mL}$ Na2CO3: x mL CDs: 8-x mL distilled: $50 \mu \mathrm{L} \mathrm{pH} 12.5$ buffer, with $x$ varying between $2.5 \mathrm{~mL}$ and $50 \mu \mathrm{L}$. The absorbance was measured at $554 \mathrm{~nm}$ with a UV-vis spectrophotometer (SHIMADZU, Japan). Each calibration curve was done in triplicate.

\subsubsection{DETERMINATION OF THE CONCENTRATION OF CYCLODEXTRINS RELEASED}

$0.02 \mathrm{~g}$ of samples was immersed in $5 \mathrm{~mL}$ of distilled water for various durations. $3 \mathrm{~mL}$ of releasing solutions was retrieved and mixed with $50 \mu \mathrm{L}$ PhP: $50 \mu \mathrm{L}$ Na2CO3: $1 \mathrm{~mL}$ distilled water and 50 $\mu \mathrm{L}$ buffer $\mathrm{pH}$ 12.5. The absorbance of the solutions was measured at $554 \mathrm{~nm}$, and the concentration of cyclodextrins was calculated accordingly to the calibration curves.

\section{RESULTS AND DISCUSSION}

\subsection{MATERIALS}

The carboxylic content of the toCNF suspension determined by conductimetric titrations was 1088 $\pm 14 \mu \mathrm{mol} / \mathrm{gtoCNF}$, which corresponds to a grafting rate of $0.176 \pm 2$. For ITC experiments, an estimated molar mass for toCNF is needed. Since the molar mass of regular AGU $\left(\mathrm{C}_{6} \mathrm{H}_{10} 0_{5}\right)$ is 162.1 $\mathrm{mol} / \mathrm{g}$, and the molar mass of the oxidized AGU $\left(\mathrm{C}_{6} \mathrm{H}_{8} \mathrm{O}_{6}\right)$ is $176.1 \mathrm{~mol} / \mathrm{g}$, the molar mass of the toCNF suspension, according to the charge level, is $164.60 \pm 0.03 \mathrm{~mol} / \mathrm{g}$. Figure 1 illustrates the appearance of toCNF in various forms and at different scales. Figure 1.A) presents the suspension of toCNF at $0.8 \mathrm{wt} \%$, displaying its viscous properties. Figure 1.B) displays the morphology of the individual nanofibrils. Figure 1.C) shows the toCNF cryogel produced by freeze-drying and Figure 1.D) illustrates its porous structure with SEM image of a cryogel cross section. 


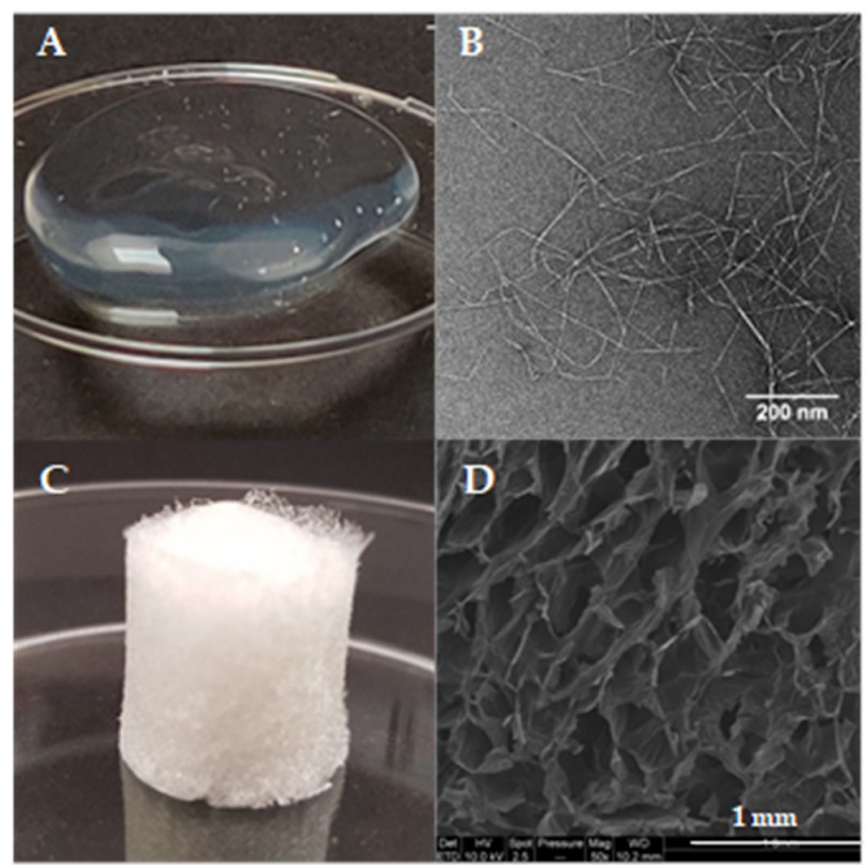

FIGURE 1 : Different forms and scales of toCNF. A) toCNF suspension B) TEM image of toCNF C) toCNF cryogel D) SEM image of the porous structure of the cryogel.

The molar mass of the cyclodextrins was calculated according to the degree of substitution provided by the different suppliers. For poly $\beta-C D$, which consists of $\beta-C D$ linked through epoxy linkage, the molar mass of the repeating unit was estimated considering the molar mass of $\beta-C D$ and the one of the epoxy functional group. Figure $2 \mathrm{~A}$ presents a schematic representation of $\beta$ $\mathrm{CD}$, while figure $2 \mathrm{~B}$ shows the modified cyclodextrins used in this study.

A

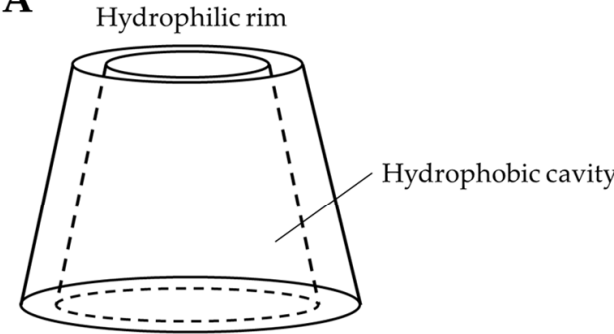

Hydrophilic rim

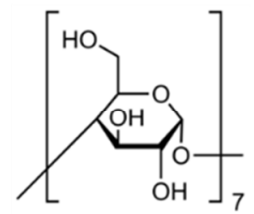

$\beta$-Cyclodextrin
B

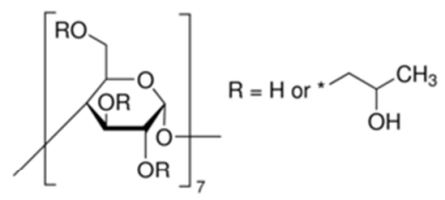

2-Hydroxypropyl- $\beta$-Cyclodextrin

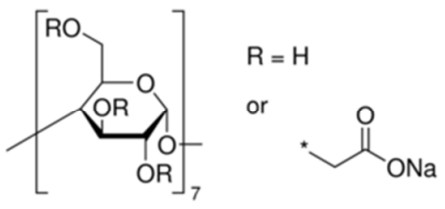

Carboxymethyl- $\beta$-Cyclodextrin Sodium Salt

Figure 2: $\beta-C D$ and its derivatives. A) Schematic representation and formula of $\beta-C D$. B) Formula of HP- $\beta-C D$ and CM- $\beta-C D$. 


\subsection{POROSITY AND WATER SORPTION}

The porosity of the cryogels and their absorbency capacity were measured at room temperature. The absorbency capacity of the cryogels is linked to their porosity, hence capillary forces are the driving mechanism of the absorption of the liquid in the structure, but also to the potential swelling of the fibers. Hence, a theoretical curve can be plotted, corresponding to a theoretical case where all the porosity of the materials is occupied with water, calculated using equation 5 :

$$
\text { Absorbency capacity }=\left(\frac{\text { Porosity }}{1-\text { Porosity }}\right) \times \frac{\rho_{\text {water }}}{\rho_{\text {cellulose }}}
$$

According to Sayeb et al. [41], results below this curve indicate that there is collapse in the porous structure, decreasing the absorbency capacity of the porous material, while results above this curves indicate that the sorption properties of the structures is not only due to the capillary forces, but also to the swelling of the fibers that make up the structure. Both theoretical curve and experimental results are presented in Figure 3.

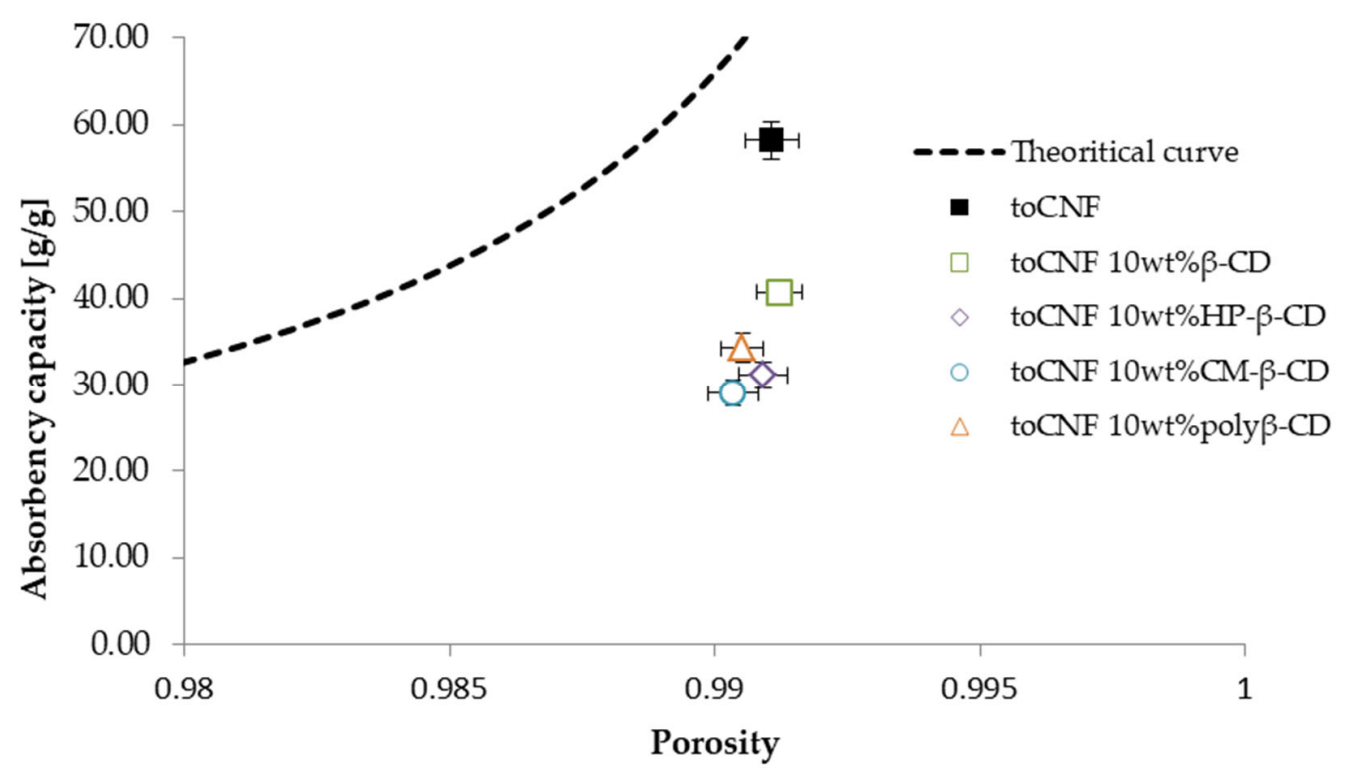

Figure 3 : Absorbency capacity of toCNF cryogels with various $\beta$-cyclodextrins.

All cryogels displayed porosity values higher than 99\%, meaning that the addition of cyclodextrins does not impact the macroscopic arrangement of porosity in the structures. All cryogels are below the theoretical curve, meaning that there is some collapse of the cell wall structure, linked to deflection in the cell wall arrangement. However, it can be noted that the pure toCNF sample exhibits a much higher absorbency capacity $(58.2 \pm 2.1 \mathrm{~g} / \mathrm{g})$ than modified aerogels and is much closer to the theoretical curve. In this case, the collapse of some pores can be linked to the presence of residual fibers. All the modified cryogels present a lower absorbency capacity, which can be linked to the adsorption of CDs on the surface of the nanofibrils, creating small deflect in the cell walls. This adsorption of $\beta-C D$ on toCNF and its impact over water sorption properties and mechanical properties of cryogels have been discussed in a previous study [32]. The absorbency capacity for toCNF with $\beta$-CD is slightly higher $(40.8 \pm 1.5 \mathrm{~g} / \mathrm{g})$ than for the samples with HP- $\beta$-CD $(31.1 \pm 1.3 \mathrm{~g} / \mathrm{g}), \mathrm{CM}-\beta-\mathrm{CD}(29.0 \pm 1.2 \mathrm{~g} / \mathrm{g})$ and poly $\beta-\mathrm{CD}(34.3 \pm 1.7 \mathrm{~g} / \mathrm{g})$. This is an indication that there is slightly more adsorption of modified $\beta$-CDs on toCNF than for 
the regular one. However, this method is only an indirect method and is not enough to be able to conclude more precisely on this issue.

\subsection{ISOTHERMAL TITRATION CALORIMETRY}

A series of ITC measurements were conducted in order to further understand the adsorption mechanism occurring between toCNF and $\beta-\mathrm{CD}$. However, the measurements for this kind of system present some difficulties. ITC measurement and subsequent calculations are designed for solutions. As toCNFs are non-soluble in water and give quite viscous suspensions at low concentrations, tests have been made to determine the ideal toCNF concentration for the suspension. They should not be too viscous to ensure a good homogeneity and mobility of cyclodextrins during the titration. The concentration used in this study was $2 \mathrm{mg} / \mathrm{mL}$. Additionally, to be able to perform calculations according to the Langmuir adsorption isotherm, which is included in the MicroCal PEAK ITC analysis software, to calculate the binding parameters (enthalpy $\Delta \mathrm{H}$, entropy $\Delta \mathrm{S}$, binding constant $\mathrm{K}_{\mathrm{D}}$, stoichiometry $\mathrm{N}$ ), the molar ratio between the two molecules of interest needs to be known. Since no specific interactions should occur, the hypothesis that was chosen is to consider that the adsorption of cyclodextrins on toCNFs is mainly linked to the presence of hydroxyl groups on the C2, C3 and C6 carbons of the AGU units, as well as on the carboxylic functions present at $\mathrm{C} 6$ on the oxidized AGU unit. Hence the estimated molar mass of toCNF taking into account its charge level was used for the calculations. The concentration of $2 \mathrm{mg} / \mathrm{mL}$ used will then corresponds to a molar concentration of $12.1 \mathrm{mM}$. Finally, since the interactions between $\mathrm{CDs}$ and toCNF are non-specific interactions, $\Delta \mathrm{H}$ can be too weak to be measured. The concentrations of $\beta-C D$ and toCNF needed to be adjusted in order to be able to obtain a measurement. The use of $\beta-C D$ at $1 \mathrm{mM}$ and toCNF at $2 \mathrm{mg} / \mathrm{mL}(12.1$ $\mathrm{mM}$ ) were found to be the best compromise. Figure 4 shows typical titration data of $\beta$-CD to toCNF. Thethermogram is represented at the top, where each peak corresponds to one injection of the $\beta-C D$ solution. Integration of this curve and subtraction of the dilution enthalpy obtained after the blank experiments lead to the titration represented in the bottom curve, with the fit calculated using the analysis software. Additionally, the binding capacity was calculated by dividing the stoichiometry $\mathrm{N}$ by the molar mass of toCNF. The results of the analysis of the binding isotherms are summarized in Table 1. 

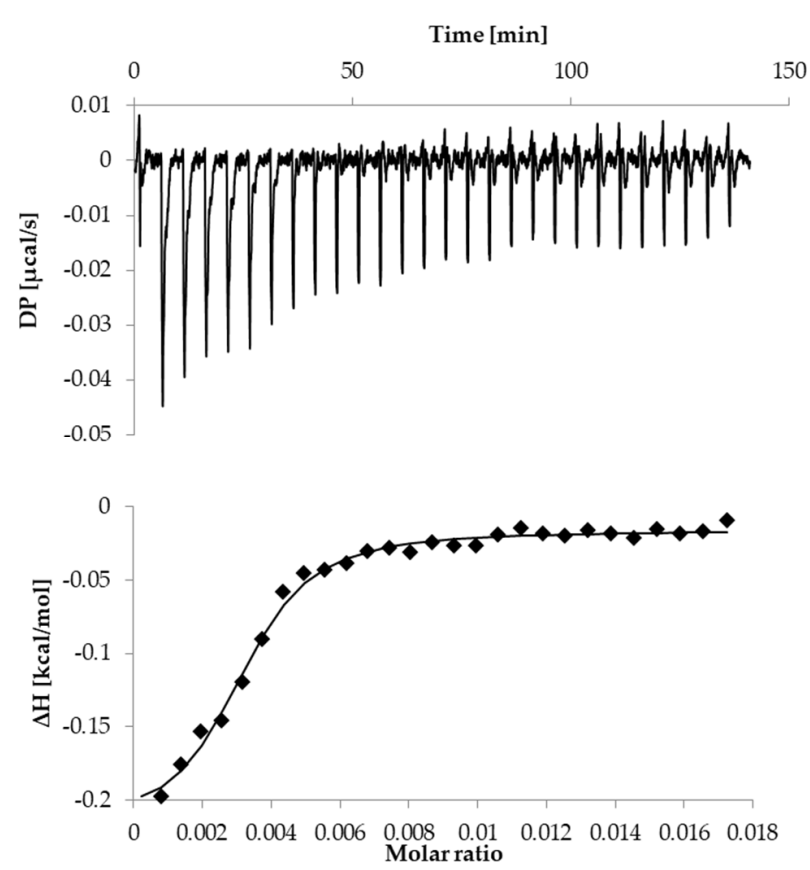

Figure 4 : Raw thermogram (at the top) and enthalpic curves and fit (at the bottom) of an ITC titration for toCNF ( $2 \mathrm{mg} / \mathrm{ml}) \mathrm{by} \mathrm{a}$ solution of $\beta-C D(1 \mathrm{~mm})$ at $25^{\circ} \mathrm{C}$.

Table 1 : Calculated thermodynamic parameters from ITC measurements

\begin{tabular}{|c|c|c|c|c|}
\hline Temperature & $\mathbf{N}$ & $\begin{array}{c}\text { Binding capacity } \\
{[\mu \mathrm{mol} / \mathrm{g}]}\end{array}$ & $\begin{array}{c}\text { Calculated } K_{\mathrm{D}} \\
{[\mathrm{M}]}\end{array}$ & $\begin{array}{c}\Delta \mathrm{H} \\
{[\mathrm{kcal} / \mathrm{mol}]}\end{array}$ \\
\hline $25^{\circ} \mathrm{C}$ & $3.1 \mathrm{e}-3$ & 19.4 & $4.58 \mathrm{e}-6$ & -0.204 \\
\hline $35^{\circ} \mathrm{C}$ & $3.2 \mathrm{e}-3$ & 18.8 & $17.1 \mathrm{e}-6$ & -0.161 \\
\hline
\end{tabular}

The weak values of enthalpy observed, as well as the dissociation constant in the micromolar range indicate that non-specific interactions occur between $\beta-C D$ and toCNF. The enthalpy is weaker at $35^{\circ} \mathrm{C}$ than at $25^{\circ} \mathrm{C}$, and the calculated $\mathrm{KD}_{\mathrm{D}}$ value is slightly higher at $35^{\circ} \mathrm{C}$ than at $25^{\circ} \mathrm{C}$, with value of respectively $17.1 \mathrm{e}-6 \mathrm{M}$ and $4.58 \mathrm{e}-6 \mathrm{M}$. Since the physical adsorption decreases with temperature, this is consistent with the hypothesis that cyclodextrins are physically adsorbed on the surface of the fibrils. The stoichiometry is similar between the two tested temperatures, and indicates that approximately $300 \mathrm{CNF}$ glucose subunits are needed for binding to one cyclodextrin. To the best of our knowledge, this is the first report of ITC measurement between $\mathrm{CNF}$ and cyclodextrins; hence there is no literature to compare these values with existing data. However, the estimated binding capacity, $19.4 \mu \mathrm{mol} / \mathrm{g}$ at $25^{\circ} \mathrm{C}$ and $18.8 \mu \mathrm{mol} / \mathrm{g}$ at $35^{\circ} \mathrm{C}$, can be compared to the binding capacity of some drugs onto CNF materials reported by Kolakovic et al. [42]. Our values are significantly higher than those reported in this study (a few $\mu \mathrm{mol} / \mathrm{g}$ depending on the drug compared to about $20 \mu \mathrm{mol} / \mathrm{g}$ for our system). The estimated value for the binding capacity needs to be considered with cautions. Indeed, these calculations were made using Langmuir isotherm. This isotherm is based on three assumptions: i) No multilayer adsorption, ii) Identical binding sites and homogeneous surfaces and iii) no interaction between adsorbed molecules. The toCNF/ $\beta$-CDs system studied here does not fully respect these 
assumptions, since potential interaction can occur between $\beta$-CDs or between two toCNF AGU by hydrogen bonding, and that we might not have identical binding sites. However, as explained by Lombardo et al. [33], this model has been the most widely used in the literature for adsorption studies on nanocellulose surface, and has been shown to fit quite well the experimental data, while other, more complicated models, have shown other limitations. Thus, this can be considered as a good approach to obtain an order of magnitude for the binding capacity of $\beta$-CDs on toCNF. This measurement leads to the conclusion that $\beta$-CDs do adsorbed onto toCNF under the tested conditions, and that the strength of adsorption is relatively low and mainly driven by electrostatic forces. Given the charges present in the toCNF suspension, it would be interesting to perform these measurements at acidic $\mathrm{pH}$. However, at the concentrations tested, acidic $\mathrm{pH}$ greatly increases the viscosity of the suspension, making the measurement impossible. Nevertheless, this first adsorption measurement between $\beta$-CDs and toCNF is a great step towards a better characterization of this system.

\subsection{QUARTZ CRISTAL MICROBALANCE WITH DISSIPATION MONITORING}

To test the capacity of toCNF in adsorbing the various CDs, surfaces were generated in situ on the QCM-d by flowing the substrate and once stabilized, flowing the CDs until stabilization. Gold sensors were cleaned and activated with a piranha bath, followed by a spin-coating of PEI as anchoring polymer on which the toCNF were then adsorbed. The sensograms were split to facilitate discussion, with the first part being the surface generation, presented in Figure 5, and the second part being the adsorption of the various $\beta$-CDs, presented in Figure 4 . Only the third overtone is presented here.

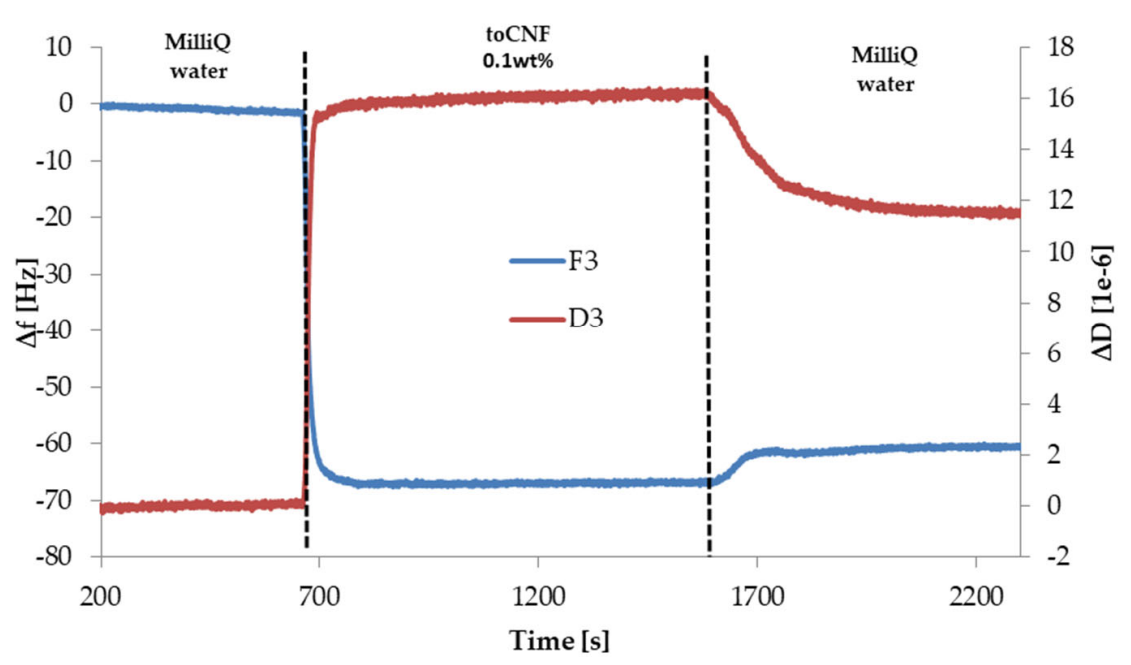

Figure 5 : QCM-d sensograms of the in-situ surface generation from toCNF

For all surfaces generated in situ, the frequency change during toCNF flow was observed to be between $-50 \mathrm{~Hz}$ and $-65 \mathrm{~Hz}$, and a dissipation shift comprised ranging from 12 to $18 \mathrm{ppm}$, showing good consistency in the approach. It can also be observed that during the rinsing step following the adsorption of toCNF, there was a diminution in the frequency shift of few $\mathrm{Hz}$, as well as a decrease in the dissipation shift, which is linked to the loss of some toCNF materials that were not strongly adsorbed on PEI. A double flow protocol, i.e. flowing a second time the toCNF suspension after the rinsing phase, has been tested but did not show any beneficial impact or 
improvement in the quantity of toCNF adsorbed. The method presented here has been used for all the experiments, the first rinsing phase allowing to evacuate the toCNF materials not bound to PEI, and the values of frequency and dissipation shift for the surface functionalization are consistent with those reported in the literature [31], [43]. The advantages of this method compared with an ex-situ preparation by spin coating is that it enables the calculation of the adsorbed mass on the sensors using the Sauerbrey equation, thus calculation of the binding capacity of the adsorbate, in this case CDs. The frequency shift used for the calculations is the frequency shift after the rinsing step.

Sensograms corresponding to the adsorption of CDs are presented in Figure 6 . The frequency shift and dissipation shift after the rinsing step are displayed in Table 2, along with the calculated adsorbed mass of CDs and an estimated binging capacity, obtained by dividing the adsorbed mass by the molar mass of the corresponding cyclodextrin.

Table 2 : Frequency shift $(\Delta \mathrm{f})$, dissipation shift $(\Delta \mathrm{D})$, adsorbed mass and estimated binding capacity for the adsorption of various $\beta$-CDs on toCNF surfaces.

\begin{tabular}{ccccc}
\hline CDs & $\begin{array}{c}\Delta \text { f after rinsing } \\
{[\mathrm{Hz}]}\end{array}$ & $\begin{array}{c}\Delta \mathrm{D} \text { after rinsing } \\
{[\mathrm{ppm}]}\end{array}$ & $\begin{array}{c}\text { Adsorbed mass } \\
{\left[\mathrm{mg} / \mathrm{g}_{\mathrm{toCNF}}\right]}\end{array}$ & $\begin{array}{c}\text { Estimated binding } \\
\text { capacity } \\
{\left[\mu \mathrm{mol} / \mathrm{g}_{\mathrm{toCNF}}\right]}\end{array}$ \\
\hline$\beta-\mathrm{CD}$ & -0.7 & 0.6 & 15.2 & 13.4 \\
HP- $\beta-\mathrm{CD}$ & -1.7 & 2.48 & 42.4 & 30.7 \\
CM- $\beta$-CD & -4.05 & 1.35 & 67.3 & 47.6 \\
Poly $\beta-C D$ & -1.3 & 1.05 & 25 & 21.0 \\
\hline
\end{tabular}




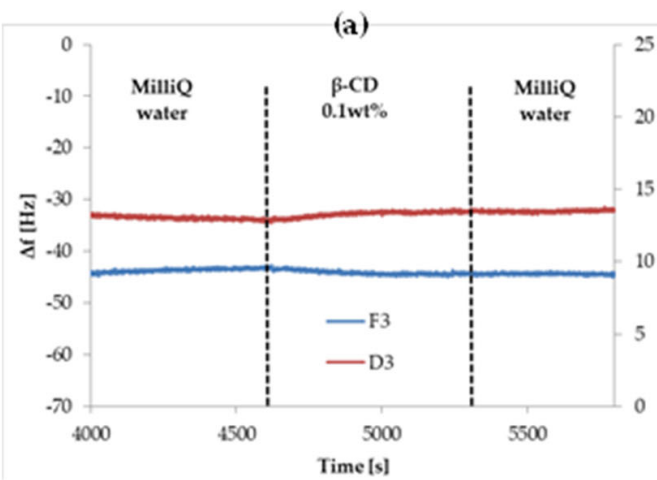

(c)

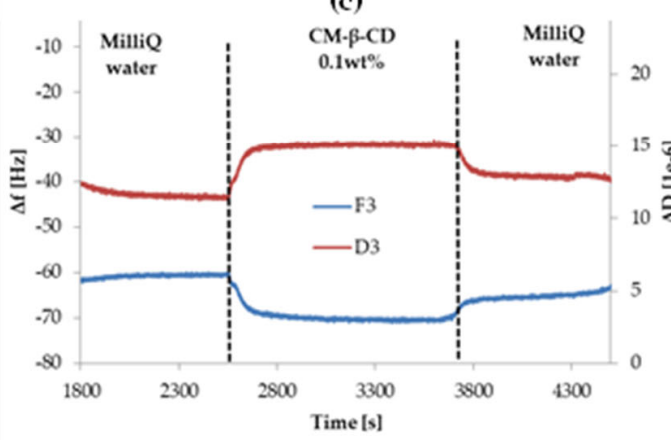

(b)

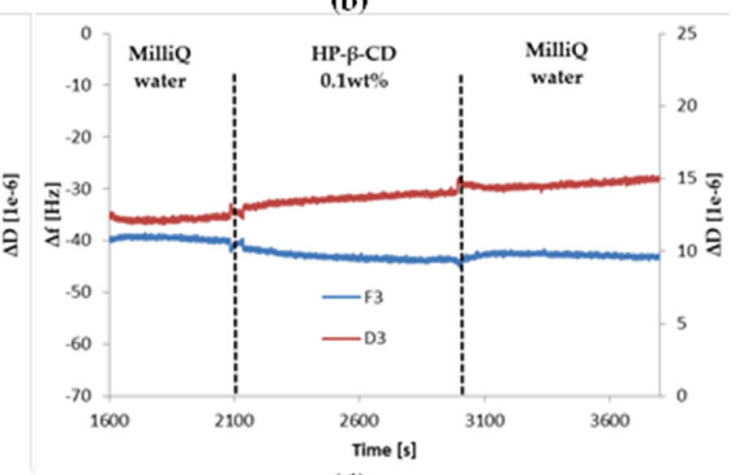

(d)

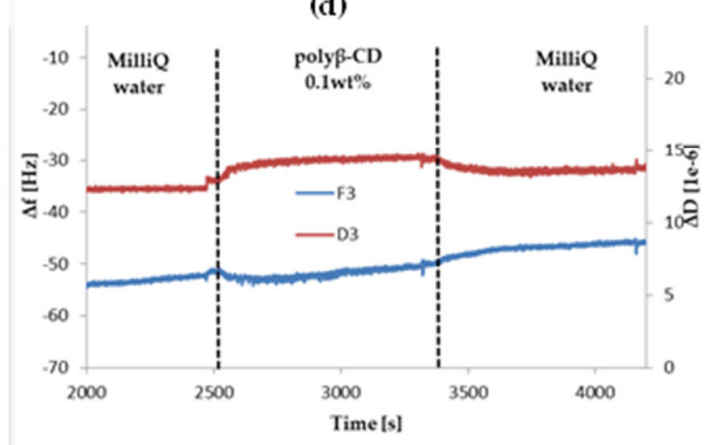

Figure 6 : QCM-d sensograms for the adsorption of (a) $\beta-C D$, (b) HP- $\beta-C D$, (c) CM- $\beta-C D$ and (d) poly $\beta-C D$ on toCNF surfaces

For the adsorption of $\beta$-CDs on the toCNF surface (Figure $4 a$ ), the frequency shift only amounted $-0.7 \mathrm{~Hz}$, which corresponds to $15.2 \mathrm{mg} / \mathrm{g}_{\mathrm{toCNF}}$ and can be regarded too low to consider that an adsorption phenome occurs. However, the dissipation shift higher than $0.5 \mathrm{ppm}$ indicates that molecular adsorption is occurring. The estimated binding capacity of $13.4 \mu \mathrm{mol} / \mathrm{g}_{\mathrm{toCNF}}$ for $\beta-\mathrm{CD}$ is of the order of magnitude of the one estimated from ITC experiments. This proves that adsorption, although weak, is occurring between $\beta-C D$ and toCNF under the tested conditions. The poly $\beta-C D$ displayed slightly higher adsorption, with a mass adsorbed of $25 \mathrm{mg} / \mathrm{g}_{\mathrm{toCNF}}$, a dissipation shift of

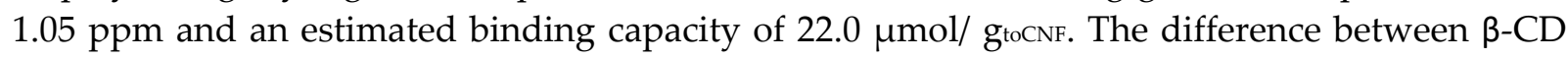
and poly $\beta-C D$ can be explained by the polymerized form of poly $\beta-C D$. Indeed, by adsorbing cyclodextrin units of the poly $\beta-C D$, the material can retain the cyclodextrin units linked to the adsorbed one. The chemical make-up of the CDs seems to be an important parameter towards the adsorption phenomena occurring between $\mathrm{CDs}$ and toCNF, as displayed by the estimated binding capacity for both HP- $\beta-C D$ and CM- $\beta-C D$, with respectively $30.7 \mu \mathrm{mol} / \mathrm{g}_{\text {toCNF }}$ and $47.6 \mu \mathrm{mol} / \mathrm{g}_{\text {toCNF. }}$ The presence of the added chemical functions for these modified $\beta$-CDs increases the possibility of forming $\mathrm{H}$-bonding with toCNF, hence increasing the adsorption. It is worth noting that for $C M-\beta-C D$, the rinsing step has more impact on the frequency shift, meaning that the flow of water removes a higher proportion of adsorbed $C M-\beta-C D$ s than for other CDs, which can be due to some repulsion between the carboxylate functions of both $C M-\beta-C D$ and toCNF. However, these measurements show that $\beta$-CDs are adsorbed onto toCNF and that the modified $\beta$-CDs displayed higher adsorption capacity, meaning that the adsorption phenomena are at least partially driven by chemical interactions.

\subsection{PhP PROTOCOL}


It is difficult to estimate the quantity of cyclodextrins still present in cryogels after contact or immersion in the liquid medium. Hence, it was decided to use a phenolphthalein-based method, previously reported by Basappa et al. [41] and adapted by De Castro et al. [30]. Phenolphthalein is a phenolate ion which is purple in alkaline conditions and loses its color when included inside a $\beta$-CD cavity. The absorbance intensity at $554 \mathrm{~nm}$ for a PhP solution depends on the alkalinity of the medium, hence the mixing of $\mathrm{PhP}$ with a $\mathrm{Na}_{2} \mathrm{CO}_{3}$ solution of controlled concentration to ensure consistency between the measurements [44]. Calibration curves were built by measuring the absorbance at $554 \mathrm{~nm}$ for $\mathrm{PhP} / \mathrm{Na} 2 \mathrm{CO} 3$ solutions with various amounts of $\mathrm{CDs}$. It appeared that linear zones were obtained by plotting

$$
\log (A b s 554 \mathrm{~nm})=A \times \log ([C D])+B
$$

With $A$ being the slope and $B$ the intercept. For each individual $\beta$-CDs, the calibration curves were performed in triplicate. Figure 7 presents for each $\beta$-CDs the mean calibration curve obtained by averaging the values obtained for each triplicate. Table 3 presents the data obtained for the linear ranges.

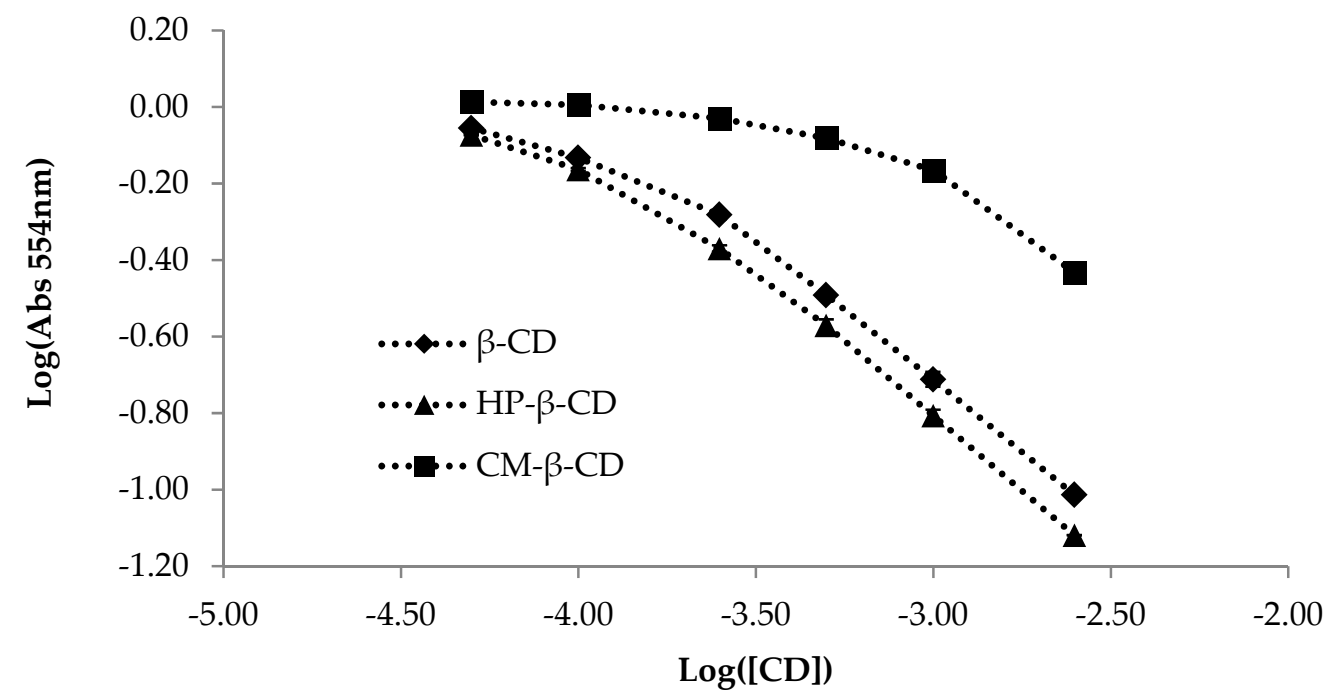

Figure 7 : Calibration curves for the various CDs with PhP

Table 3 : Data obtained from the calibration plots for the various CDs estimated by the PhP protocol. Slope and intercept values are for the linear portion of the curve.

\begin{tabular}{cccccc}
\hline CDs & $\begin{array}{c}\text { Linear range } \\
{[\mathrm{mM}]}\end{array}$ & Slope & Intercept & Mean SD & $\begin{array}{c}\text { Correlation } \\
\text { coefficient }\end{array}$ \\
\hline$\beta-\mathrm{CD}$ & $0.1-2.5$ & -0.643 & -2.650 & 0.008 & 0.9827 \\
HP- $\beta-\mathrm{CD}$ & $0.1-2.5$ & -0.690 & -2.884 & 0.002 & 0.9917 \\
$\mathrm{CM}-\boldsymbol{\beta}-\mathrm{CD}$ & $/$ & $/$ & $/$ & 0.009 & $/$ \\
\hline
\end{tabular}

It can be observed that the calibration curves obtained for $\beta-C D$ and $H P-\beta-C D$ show a great similarity, with a linear range for $\beta$-CDs concentration between $0.1 \mathrm{mM}$ and $2.5 \mathrm{mM}$ and a good correlation coefficient. The low standard deviation obtained also proves a good consistency of the method. These calibrations curves can therefore be used for the calculation of the concentrations 
of $\beta-C D$ and $H P-\beta-C D$ in a solution mixed with the working solution of PhP. For CM- $\beta-C D$, in the concentration range used, no linear zone can be observed, therefore no slope and intercept can be calculated. This can be explained by the modification of the chemical environment of the internal cavity of $C M-\beta-C D$, due to the presence of carboxylate ions. This leads to a modification of the inclusion properties, which was not observed for $\beta-C D$ and HP- $\beta-C D$. However, the low standard deviation obtained proves a good consistency, meaning that this curve can be used to approximate the concentration of cyclodextrins in the solutions mixed with the working solution of $\mathrm{PhP}$ by framing the values obtained with reference values.

These data were used to calculate the amount of $\beta$-CD released from cryogels upon immersion for various release times in distilled water. The release volume was chosen based on the mass of CDs in the cryogels so that the $\mathrm{CD}$ concentrations were in the linear range of the calibration curves. The release medium was then sampled and mixed with the PhP working solution and the absorbance was measured at $554 \mathrm{~nm}$. The concentrations of $\beta-C D$ and HP- $\beta-C D$ were calculated using the data of their respective calibration curves. The poly- $\beta-C D$ concentration was calculated using the calibration data of $\beta-C D$. The $C M-\beta-C D$ concentration was approximated using the reference values of the calibration curve. The percentage of $C D$ released was calculated from the initial mass of CD in the cryogels, the volume of release medium, the volume of the sampled released medium, the volume of the analyzed solution and the measured or approximated concentration. The results are displayed in Figure 8.

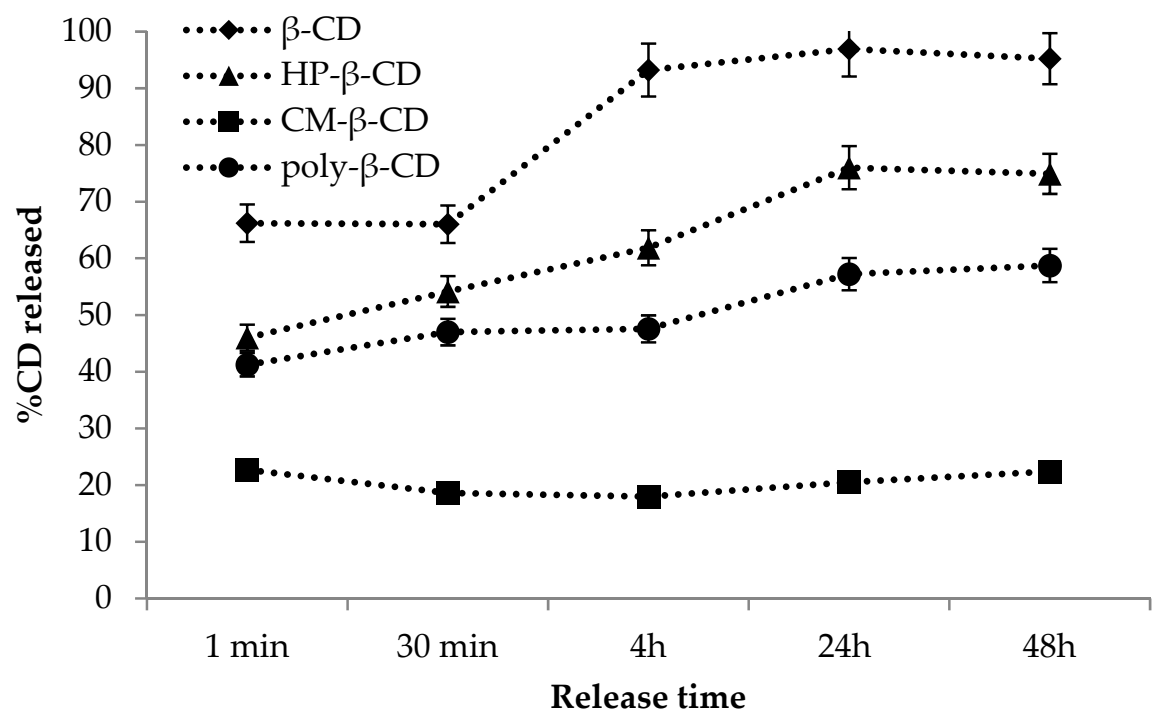

Figure 8 : Release profile for $\beta$-CDs from toCNF cryogels

$\beta-C D$ is the most released CDs, with around $65 \%$ of the total amount released after 1 min and up to $95 \%$ after $24 \mathrm{~h}$. The increase in the amount of cyclodextrins release with time can be explained by the swelling of the cryogels and the physical entanglement of some cyclodextrins. This increase with time of release is observed for HP- $\beta-C D$, with around $45 \%$ of CD released after 1 minute up to $75 \%$ after $24 \mathrm{~h}$, and for poly $\beta-C D$, with around $40 \%$ after 1 minute up to $58 \%$ after $24 \mathrm{~h}$. It is worth noting that the values of \%CD released do not vary much between $24 \mathrm{~h}$ and $48 \mathrm{~h}$ of release time, meaning that a plateau is reached. For $C M-\beta-C D$, the approximated amount of $C D$ released remains roughly constant with the release time, and it is estimated around $20 \%$. These results 
indicate that the adsorption is stronger between modified cyclodextrins and toCNF than between raw $\beta$-CD and toCNF, confirming the observation made with QCM-d. Since the quantity of CDs introduced in the cryogels is known, as well as their respective molar mass, it is possible to calculate the amount of $\mathrm{CD}$ in $\mu \mathrm{mol} / \mathrm{g}$ for each type of CDs. By comparing this quantity with the estimated binding capacity determined by QCM-d, an estimation of the percentage of cyclodextrin released can also be calculated. These data are presented in Table 4 .

Table 4 : Estimation of $\beta$-CDs release from toCNF cryogels

\begin{tabular}{|c|c|c|c|}
\hline CDs & $\begin{array}{l}\text { Amount of CDs in the } \\
\text { sample }\left[\mu \mathrm{mol} / \mathrm{g}_{\mathrm{toCNF}}\right]\end{array}$ & $\begin{array}{c}\text { Estimated binding } \\
\text { capacity by QCM-d } \\
{\left[\mu \mathrm{mol} / \mathrm{g}_{\mathrm{toCNF}}\right]}\end{array}$ & $\begin{array}{c}\text { Estimated } \% C D \\
\text { released }(\mathrm{QCM}-\mathrm{d})\end{array}$ \\
\hline$\beta-C D$ & 88.1 & 13.4 & 84.8 \\
\hline$H P-\beta-C D$ & 72.5 & 30.7 & 57.6 \\
\hline$C M-\beta-C D$ & 70.7 & 47.6 & 32.7 \\
\hline Poly $\beta-C D$ & 84.0 & 22.0 & 73.8 \\
\hline
\end{tabular}

The comparison between these calculations and the results obtained with the $\mathrm{PhP}$ protocol are presented in Figure 9. These results need to be considered with cautions. Indeed, the values of binding capacity determined by QCM-d are calculated according to a mass of CD adsorbed on a thin film, while the $\mathrm{PhP}$ protocol was used on cryogels. Additionally, the adsorbed mass was calculated in QCM-d with the Sauerbrey equation and considering low frequency drop, which can induce some uncertainties in the calculations. Considering this, we can observe that the estimated percentage of $\mathrm{CD}$ released is quite close to the measured one, confirming the observation of adsorption between toCNF and CDs, with stronger adsorption for modified CDs, especially for $\mathrm{CM}-\beta-\mathrm{CD}$.

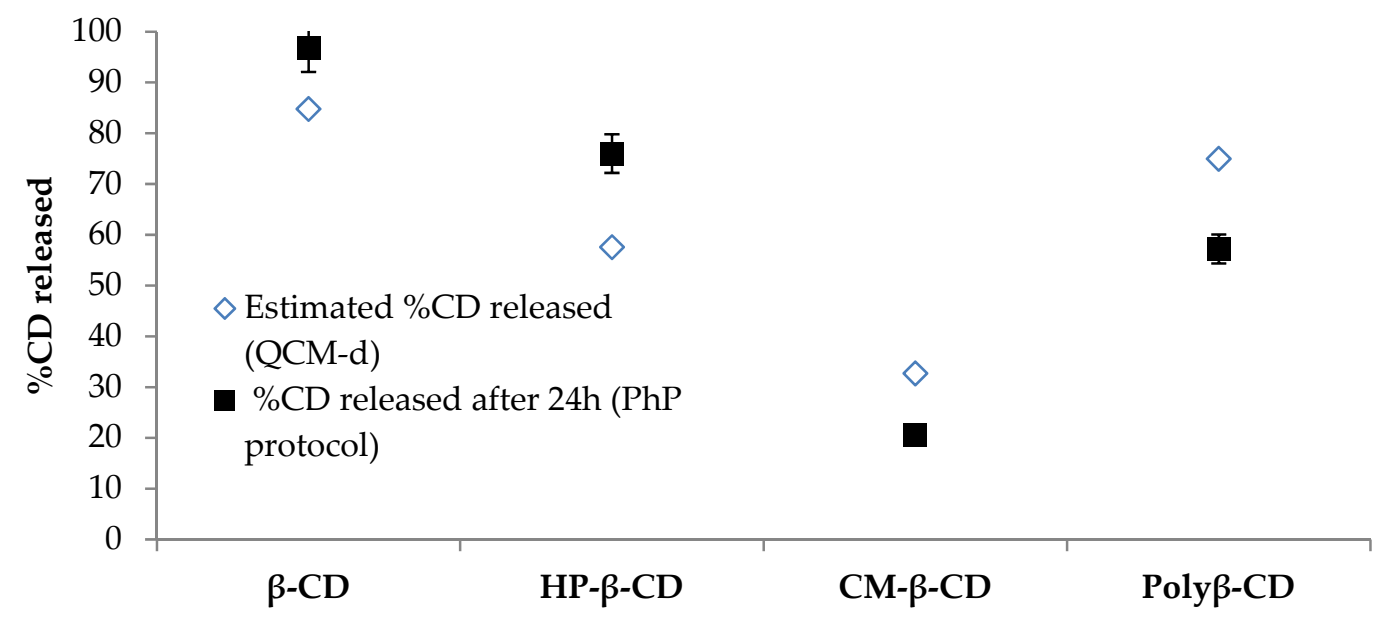

Figure 9 : Comparison between estimated and measured $\beta$-CDs release from toCNF cryogels

For poly $\beta-C D$, the increased adsorption in comparison with $\beta-C D$ can be explained by the potential entanglement of the long chains with the nanofibers. For modified $\beta$-CDs, the difference 
in adsorption is supposed to be chemically driven, with difference in the accessibility of hydroxyl groups, which is higher for modified CDs due to the functional groups added. In order to go further in the understanding of the observed phenomena, it would be relevant to set up measurements allowing to compare this accessibility of the hydroxyl groups between the CDs, but also to evaluate the strength of the resulting hydrogen bonds.

\section{CONCLUSION}

In this study, we have investigated the adsorption of various $\beta$-CDs onto toCNF materials via different experimental means. The impact of the adsorption on the absorbency capacity of cryogels was assessed. The adsorption of $\beta$-CD onto toCNF in suspension was measured via Isothermal Titration Calorimetry, which has, to the best of our knowledge, not been reported previously. QCM-d experiments were conducted to determine the binding affinity for the different CDs and showed that modified $\beta$-CDs exhibit a higher binding capacity to toCNF than raw $\beta$-CD. This observation was confirmed by measuring the percentage of cyclodextrin released from the cryogels, assessed with a phenolphthalein-based protocol, which confirmed that modified cyclodextrins are more strongly adsorbed on toCNF. These measurements will help to design optimized cyclodextrin-modified-toCNF materials, which can be beneficial for numerous applications, such as biomedical or depollution.

\section{ACKNOWLEDGMENTS}

This work is supported by the French National Research Agency in the framework of the "Investissements d'avenir" program Glyco@Alps (ANR-15-IDEX-02) and NTNU through its Department of Chemical Engineering. LGP2 is part of the LabEx Tec 21 (Investissements d'Avenir-Grant Agreement No. ANR-11-LABX-0030) and of the PolyNat Carnot Institute (Investissements d'Avenir-Grant Agreement No. ANR-16-CARN-0025-01). This research was made possible thanks to the facilities of the TekLiCell platform funded by the Région Rhône-Alpes (ERDF: European regional development fund). The authors acknowledge J. Viguié (LGP2) for discussion on absorbency capacity and porosity, E. Gillon (Cermav) for lab support with ITC, Y. Navon (CTP) for access to QCM-d, C. Lancelot-Pin (Cermav) for TEM images.

\section{REFERENCES}

[1] O. Nechyporchuk, M. N. Belgacem, et J. Bras, «Production of cellulose nanofibrils: A review of recent advances", Industrial Crops and Products, vol. 93, p. 2-25, déc. 2016, doi: 10.1016/j.indcrop.2016.02.016.

[2] T. Saito et A. Isogai, « Introduction of aldehyde groups on surfaces of native cellulose fibers by TEMPO-mediated oxidation", Colloids and Surfaces A: Physicochemical and Engineering Aspects, vol. 289, no 1-3, p. 219-225, oct. 2006, doi: 10.1016/j.colsurfa.2006.04.038.

[3] T. Abitbol et al., "Nanocellulose, a tiny fiber with huge applications ", Current Opinion in Biotechnology, vol. 39, p. 76-88, juin 2016, doi: 10.1016/j.copbio.2016.01.002.

[4] M. A. Hubbe et al., "Nanocellulose in Thin Films, Coatings, and Plies for Packaging Applications: A Review», BioResources, vol. 12, no 1, p. 2143-2233, févr. 2017, doi: 10.15376/biores.12.1.2143-2233. 
[5] D. Klemm et al., "Nanocellulose as a natural source for groundbreaking applications in materials science: Today's state», Materials Today, vol. 21, n 7, p. 720-748, sept. 2018, doi: 10.1016/j.mattod.2018.02.001.

[6] R. Kolakovic, L. Peltonen, A. Laukkanen, J. Hirvonen, et T. Laaksonen, « Nanofibrillar cellulose films for controlled drug delivery», European Journal of Pharmaceutics and Biopharmaceutics, vol. 82, n² 2, p. 308-315, oct. 2012, doi: 10.1016/j.ejpb.2012.06.011.

[7] P. R. Sharma, S. K. Sharma, T. Lindström, et B. S. Hsiao, « Nanocellulose-Enabled Membranes for Water Purification: Perspectives », Adv. Sustainable Syst., vol. 4, no 5, p. 1900114, mai 2020, doi: 10.1002/adsu.201900114.

[8] G. Crini, S. Fourmentin, M. Fourmentin, et N. Morin-Crini, «Principales applications des complexes d'inclusion cyclodextrine/substrat », p. 21, 2019.

[9] T. Loftsson et M. E. Brewster, «Pharmaceutical applications of cyclodextrins: basic science and product development: Pharmaceutical applications of cyclodextrins ", Journal of Pharmacy and Pharmacology, vol. 62, no 11, p. 1607-1621, nov. 2010, doi: 10.1111/j.2042-7158.2010.01030.x.

[10]E. M. M. Del Valle, « Cyclodextrins and their uses: a review », Process Biochemistry, vol. 39, n 9, p. 1033-1046, mai 2004, doi: 10.1016/S0032-9592(03)00258-9.

[11]P. Blach, S. Fourmentin, D. Landy, F. Cazier, et G. Surpateanu, "Cyclodextrins: A new efficient absorbent to treat waste gas streams », Chemosphere, vol. 70, n 3, p. 374-380, 2008, doi: https://doi.org/10.1016/j.chemosphere.2007.07.018.

[12] « Cyclodextrins used as excipients », p. 16.

[13]M. Kfoury, «Préparation, caractérisation physicochimique et évaluation des propriétés biologiques de complexes d'inclusion à base de cyclodextrines: applications à des principes actifs de type phénylpropanoïdes », p. 226.

[14]S. Gould et R. C. Scott, « 2-Hydroxypropyl- $\beta$-cyclodextrin (HP- $\beta$-CD): A toxicology review », Food and Chemical Toxicology, vol. 43, no 10, p. 1451-1459, oct. 2005, doi: 10.1016/j.fct.2005.03.007.

[15] A. Z. M. Badruddoza, G. S. S. Hazel, K. Hidajat, et M. S. Uddin, « Synthesis of carboxymethyl$\beta$-cyclodextrin conjugated magnetic nano-adsorbent for removal of methylene blue », Colloids and Surfaces A: Physicochemical and Engineering Aspects, vol. 367, n 1-3, p. 85-95, sept. 2010, doi: 10.1016/j.colsurfa.2010.06.018.

[16] G. Shixiang, W. Liansheng, H. Qingguo, et H. Sukui, « SOLUBILIZATION OF POLYCYCLIC AROMATIC HYDROCARBONS BY P-CYCLODEXTRIN AND CARBOXYMETHYL-flCYCLODEXTRIN », p. 7.

[17] N. H. Foda et R. B. Bakhaidar, «Zaleplon », in Profiles of Drug Substances, Excipients and Related Methodology, vol. 35, Elsevier, 2010, p. 347-371. doi: 10.1016/S1871-5125(10)35008-4.

[18]C. Su et al., «Carboxymethyl- $\beta$-cyclodextrin conjugated nanoparticles facilitate therapy for folate receptor-positive tumor with the mediation of folic acid», International Journal of Pharmaceutics, vol. 474, no 1-2, p. 202-211, oct. 2014, doi: 10.1016/j.ijpharm.2014.08.026.

[19]N. Morin-Crini, P. Winterton, S. Fourmentin, L. D. Wilson, É. Fenyvesi, et G. Crini, « Waterinsoluble $\beta$-cyclodextrin-epichlorohydrin polymers for removal of pollutants from aqueous 
solutions by sorption processes using batch studies: A review of inclusion mechanisms », Progress in Polymer Science, vol. 78, p. 1-23, mars 2018, doi: 10.1016/j.progpolymsci.2017.07.004.

[20]B. Martel, D. Ruffin, M. Weltrowski, Y. Lekchiri, et M. Morcellet, « Water-soluble polymers and gels from the polycondensation between cyclodextrins and poly(carboxylic acid)s: A study of the preparation parameters », J. Appl. Polym. Sci., vol. 97, no 2, p. 433-442, juill. 2005, doi: 10.1002/app.21391.

[21]S. Saini, D. Quinot, N. Lavoine, M. N. Belgacem, et J. Bras, « $\beta$-Cyclodextrin-grafted TEMPOoxidized cellulose nanofibers for sustained release of essential oil », Journal of Materials Science, vol. 52, nº 7, p. 3849-3861, avr. 2017, doi: 10.1007/s10853-016-0644-7.

[22]G. Yuan et al., "Cyclodextrin functionalized cellulose nanofiber composites for the faster adsorption of toluene from aqueous solution», Journal of the Taiwan Institute of Chemical Engineers, vol. 70, p. 352-358, janv. 2017, doi: 10.1016/j.jtice.2016.10.028.

[23] C. Ruiz-Palomero, M. L. Soriano, et M. Valcárcel, « $\beta$-Cyclodextrin decorated nanocellulose: a smart approach towards the selective fluorimetric determination of danofloxacin in milk samples », Analyst, vol. 140, no 10, p. 3431-3438, mai 2015, doi: 10.1039/C4AN01967A.

[24]Z. Aytac, H. S. Sen, E. Durgun, et T. Uyar, "Sulfisoxazole/cyclodextrin inclusion complex incorporated in electrospun hydroxypropyl cellulose nanofibers as drug delivery system », Colloids and Surfaces B: Biointerfaces, vol. 128, p. 331-338, avr. 2015, doi: 10.1016/j.colsurfb.2015.02.019.

[25] N. Lavoine, N. Tabary, I. Desloges, B. Martel, et J. Bras, « Controlled release of chlorhexidine digluconate using $\beta$-cyclodextrin and microfibrillated cellulose», Colloids and Surfaces B: Biointerfaces, vol. 121, p. 196-205, sept. 2014, doi: 10.1016/j.colsurfb.2014.06.021.

[26] A. Fiorati et al., «TEMPO-Nanocellulose/Ca2+ Hydrogels: Ibuprofen Drug Diffusion and In Vitro Cytocompatibility », Materials, vol. 13, no 1, p. 183, janv. 2020, doi: 10.3390/ma13010183.

[27]D. O. Castro, N. Tabary, B. Martel, A. Gandini, N. Belgacem, et J. Bras, «Effect of different carboxylic acids in cyclodextrin functionalization of cellulose nanocrystals for prolonged release of carvacrol », Materials Science and Engineering: C, vol. 69, p. 1018-1025, déc. 2016, doi: 10.1016/j.msec.2016.08.014.

[28] A. Jimenez, F. Jaramillo, U. Hemraz, Y. Boluk, K. Ckless, et R. Sunasee, «Effect of surface organic coatings of cellulose nanocrystals on the viability of mammalian cell lines", Nanotechnology, Science and Applications, vol. Volume 10, p. 123-136, sept. 2017, doi: 10.2147/NSA.S145891.

[29]D. O. de Castro, N. Tabary, B. Martel, A. Gandini, N. Belgacem, et J. Bras, « Controlled release of carvacrol and curcumin: bio-based food packaging by synergism action of TEMPOoxidized cellulose nanocrystals and cyclodextrin », Cellulose, vol. 25, n² 2, p. 1249-1263, févr. 2018, doi: 10.1007/s10570-017-1646-6.

[30]N. Tabary et al., " A chlorhexidine-loaded biodegradable cellulosic device for periodontal pockets treatment», Acta Biomaterialia, vol. 10, $\mathrm{n}^{\circ}$ 1, p. 318-329, janv. 2014, doi: 10.1016/j.actbio.2013.09.032. 
[31]D. Gomez-Maldonado et al., "Cellulose-Cyclodextrin Co-Polymer for the Removal of Cyanotoxins on Water Sources", Polymers, vol. 11, no 12, p. 2075, déc. 2019, doi: 10.3390/polym11122075.

[32]B. Michel, J. Bras, A. Dufresne, E. B. Heggset, et K. Syverud, «Production and Mechanical Characterisation of TEMPO-Oxidised Cellulose Nanofibrils/ $\beta$-Cyclodextrin Films and Cryogels », Molecules, vol. 25, nº 10, p. 2381, mai 2020, doi: 10.3390/molecules25102381.

[33]S. Lombardo et $W$. Thielemans, « Thermodynamics of adsorption on nanocellulose surfaces », Cellulose, vol. 26, no 1, p. 249-279, janv. 2019, doi: 10.1007/s10570-018-02239-2.

[34] Y. Navon, H. Radavidson, J.-L. Putaux, B. Jean, et L. Heux, "pH-Sensitive Interactions between Cellulose Nanocrystals and DOPC Liposomes », Biomacromolecules, vol. 18, no 9, p. 2918-2927, sept. 2017, doi: 10.1021/acs.biomac.7b00872.

[35]S. Lombardo, P. Chen, P. A. Larsson, W. Thielemans, J. Wohlert, et A. J. Svagan, « Toward Improved Understanding of the Interactions between Poorly Soluble Drugs and Cellulose Nanofibers ", Langmuir, vol. 34, $\mathrm{n}^{\circ}$ 19, p. 5464-5473, mai 2018, doi: 10.1021/acs.langmuir.8b00531.

[36]R. Weishaupt et al., «TEMPO-Oxidized Nanofibrillated Cellulose as a High Density Carrier for Bioactive Molecules ", Biomacromolecules, vol. 16, no 11, p. 3640-3650, nov. 2015, doi: 10.1021/acs.biomac.5b01100.

[37]M. Rodahl, F. Höök, A. Krozer, P. Brzezinski, et B. Kasemo, "Quartz Cristal microbalance setup for frequency and Q-factor measurments in gaseous and liquid environments », Review of Scientific Instruments, vol. 66, no 3924, 1995.

[38]M. V. Voinova, M. Rodahl, M. Jonson, et B. Kasemo, «Viscoelastic Acoustic Response of Layered Polymer Films at Fluid-Solid Interfaces: Continuum Mechanics Approach », Physica Scripta, vol. 59, no 5, p. 391-396, mai 1999, doi: 10.1238/physica.regular.059a00391.

[39]K. Taguchi, « Transient binding of phenolphthalein-.beta.-cyclodextrin complex: an example of induced geometrical distortion », Journal of the American Chemical Society, vol. 108, n० 10, p. 2705-2709, mai 1986, doi: 10.1021/ja00270a032.

[40]C. Basappa, P. Rao, D. N. Rao, et Divakar, « A modified colorimetric method for the estimation of $\beta$-cyclodextrin using phenolphthalein », International Journal of Food Science E Technology, vol. 33, nº 6, p. 517-520, déc. 1998, doi: 10.1046/j.1365-2621.1998.00216.x.

[41]S. Sayeb, M. B. Hassen, et F. Sakli, « Modelling Absorption Capacity Performance of Hygienic Product », OJAppS, vol. 03, no 02, p. 169-173, 2013, doi: 10.4236/ojapps.2013.32023.

[42]R. Kolakovic et al., "Evaluation of drug interactions with nanofibrillar cellulose », European Journal of Pharmaceutics and Biopharmaceutics, vol. 85, no 3, p. 1238-1244, nov. 2013, doi: 10.1016/j.ejpb.2013.05.015.

[43]S. Ahola, M. Österberg, et J. Laine, «Cellulose nanofibrils-adsorption with poly(amideamine) epichlorohydrin studied by QCM-D and application as a paper strength additive », Cellulose, vol. 15, no 2, p. 303-314, avr. 2008, doi: 10.1007/s10570-007-9167-3.

[44] M. Mikel, « Colorimetric determination of/3-cyclodextrin" two assay modifications based on molecular complexation of phenolphtalein », p. 8 . 
